\section{Alternative Techniques to Remove Fractured Instrument Fragments from the Apical Third of Root Canals: Report of Two Cases}

Manoel Brito-Júnior ${ }^{1}$, João Américo Normanha ${ }^{1}$, Carla Cristina Camilo ${ }^{1}$, André Luis Faria-e-Silva², Paulo César Saquy', Maria Ãngela Arêa Leão Ferraz $^{3}$, Yara Teresinha Correa Silva-Sousa ${ }^{1}$

\author{
'Department of Dentistry, \\ UNIMONTES - State University \\ of Montes Claros, Montes \\ Claros, MG, Brazil \\ ${ }^{2}$ Department of Dentistry, School of \\ Dentistry, UFS - Federal University \\ of Sergipe, Aracaju, SE, Brazil \\ 3UESPI - Piauí State University, \\ Teresina, Piauí, Brazil
}

This paper describes two cases of instrument fragment removal from the apical thirds of root canals using a customized extractor and a modified needle technique, respectively. In case 1 , a customized extractor was manufactured to remove a bur fragment located in the apical root canal of a maxillary central incisor. The use of this extractor enabled successful and conservative removal of the instrument fragment. In case 2, a modified injection needle was used as a trepan to gain access around an instrument fragment located in the curved apical portion of the mesiobuccal canal of a mandibular molar. A segment of steel wire was inserted into the needle lumen to engage the metallic fragment, enabling its removal with counter-clockwise rotation and a simultaneous pull-out motion. Alternative and creative methods are useful for the management of intracanal metallic fragments during root canal treatment.
Correspondence: Prof. Dr. Manoel Brito-Júnior, Campus Universitário Prof. Darcy Ribeiro, Caixa Postal 126, Vila Mauricéia 39401-089 Montes Claros, MG, Brasil. Tel: +55-38-3229-8284. e-mail: manoelbritojunior@gmail.com

\section{Introduction}

Intracanal instrument fracture creates obstruction of the root canal by metallic fragments, which can jeopardise thorough chemomechanical debridement and compromise the outcome of root canal treatment. When such an accident is verified clinically, the fragment can be removed or bypassed and sealed within the root canal space, or true blockage can be performed (1). In most cases, removal of the fractured instrument segment is the best alternative. However, practitioners often find orthograde fragment removal to be difficult and time consuming (2).

The removal of an instrument fragment located in the apical third of the root canal is particularly complex, and attempts to do so can increase the risks of ledge formation, root perforation, and root fracture $(1,3)$. The diameter and curvature of the canal, type of fractured instrument, and amount of potential damage to the remaining tooth structure should be considered when removing fragments from this location (4).

Several removal techniques and devices have been described, including drills, extractors, ultrasonic tips, dental operating microscopes, and electrochemical processes (4-6), but no standardised procedure for the removal of intracanal metallic obstructions has been established. Traditional extractors, such as the Masserann kit [MicroMega, Besancon, France], and new extractor systems, such as the Endo Rescue kit [Komet/Brasseler, Savannah, GA, USA] are very useful for the removal of instrument fragments after intracanal fracture $(5,6)$. Usually, these extractors are used in anterior teeth with thick, straight roots or in the straight canal portions of posterior teeth (5-7). Alternative techniques include the use of injection or hypodermic needles (8), the Canal Finder system (9), needle holders (10), stainless-steel tubes and Hedström files (11), modified spreaders or K-files under ultrasonic vibration (12), file-removal systems (13), chloroform-dipped guttapercha cones (14), and microtubes with internal screw wedges (15). This report of two cases describes the use of two alternative techniques to remove fractured instruments from the apical thirds of root canals.

\section{Case Report}

Case 1

A healthy 11-year-old girl was referred to the Clinic of the Brazilian Association of Dentistry, Montes Claros, Brazil, for evaluation of the permanent maxillary left central incisor. The patient's dental history indicated that the tooth had sustained trauma approximately 1 year previously. The trauma also caused avulsion of the maxillary right central incisor, which was not reimplanted. A radiograph taken immediately after the trauma showed the absence of the maxillary right central incisor and fractured crown and open apex of the maxillary left central incisor (Fig. 1A). Root canal treatment of the maxillary left central incisor was initiated, but the patient had not returned to complete the treatment.

During clinical examination, the maxillary left central 
incisor was asymptomatic upon percussion and palpation, and no sinus tract was observed. The coronal portion of this tooth was fractured and a palatal cavity had been restored with provisional material. A pulp sensibility test (Endo-Ice; The Hygienic Corporation, Akron, OH, USA) was negative for the maxillary left central incisor, but findings were normal for adjacent teeth. A periapical radiograph of the maxillary left central incisor showed two metallic objects resembling bur fragments in the intracanal space (Fig. 1B). This radiograph also showed reduction of the apical foramen aperture, suggesting root development under these adverse conditions. Asymptomatic apical periodontitis was diagnosed on the basis of clinical and radiographic findings, and root canal treatment with an attempt to remove the intracanal metallic fragments remaining from the previous treatment was proposed.

Coronal access was obtained under local anaesthesia with rubber dam isolation. The temporary restoration was removed and the root canal entrance was identified. The coronal cavity walls were finished with an Endo-Z bur (Dentsply Maillefer, Ballaigues, Switzerland) and straightline access to the instrument fragments was achieved with \#4 and \#5 Gates-Glidden drills (Dentsply Maillefer). The root canal was irrigated with $2.5 \% \mathrm{NaOCl}$ solution and the instrument fragment was bypassed with a \#15 K-file (Dentsply Maillefer) (Fig. 1C). A small fragment was then removed using a Hedström file. The same procedure was attempted repeatedly to remove another metallic fragment located more apically, but without success. However, the bypass attempt displaced the fragment cervically and created an approximately 4- $\mathrm{mm}$ space lateral to the fragment (Fig. 1D). Given this more favourable position, ultrasonic tips were used in another attempt to remove the fragment, but without success. Thus, the canal was dressed with calcium hydroxide paste and the tooth was sealed provisionally with a non-eugenol temporary filling material (Cimpat, Septodont, Saint Maur, France).

The presence of a wide, straight root canal favoured a subsequent removal attempt with an extractor. A customized extractor was designed and fabricated (Fig. 1E) using a 6-mm section of a plastic scalp vein tube (1-mm internal diameter). One of the tube's ends was bevelled to facilitate impingement of the fragment. A handle was built up on the tube's opposite end using acrylic resin and fixer. The plastic tube and handle were then used to cast a customized extractor made of nickel-chromium alloy. The fabrication of this customized extractor is illustrated step-by-step in Figure 2.

A further attempt to remove the apically located metallic fragment was made using the customized extractor. The tooth was reopened under local anaesthesia with rubber dam isolation. The root canal was flushed with 2.5\% $\mathrm{NaOCl}$ to remove the intracanal dressing. The extractor was then inserted carefully into the root canal, lateral to the instrument fragment. Two \#30 K-files (one on each side of the fragment) were inserted into the hollow tube of the
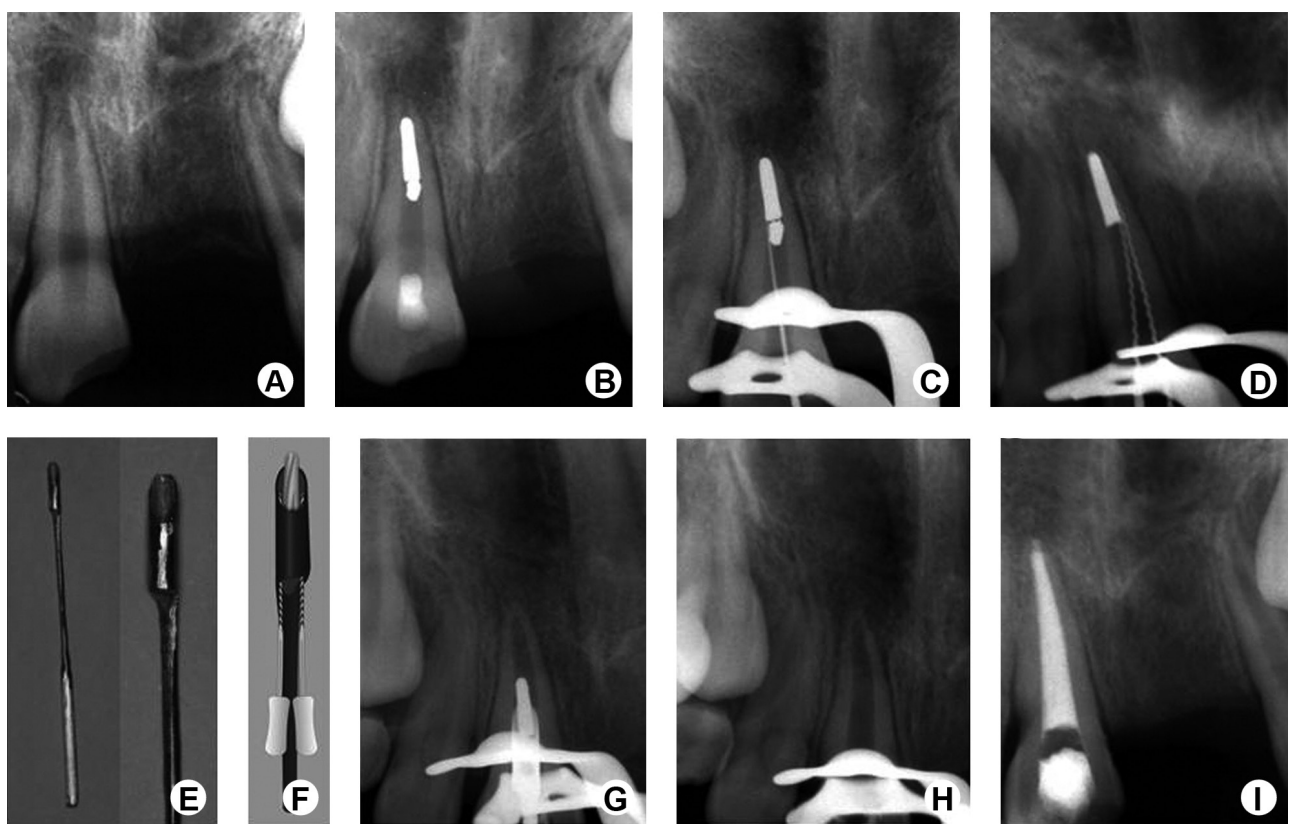

Figure 1. Sequence of fragment removal in case 1. A: A radiograph provided by the patient showing the condition of the maxillary left central incisor immediately after trauma 1 year previously. B: Preoperative radiograph showing the presence of two metallic fragments in the root canal. C: Removal of the smaller fragment. D: Attempt to remove the larger fragment using two files. E: Photograph of the cast customized extractor. F: Schematic illustration showing the insertion of Hedström files into the extractor to engage the fragment. G: Removal of the larger apical fragment using the customized extractor. H: Radiograph of the maxillary left central incisor after fragment removal. 1: Radiograph obtained after root canal filling. 
extractor to stabilise it (Fig. 1F). This procedure enabled the withdrawal of the intracanal metallic fragment attached to the extractor (Fig. 1G), unblocking the root canal space (Fig. $1 \mathrm{H})$. Thereafter, chemomechanical root canal preparation using the crown-down technique was performed. During instrumentation, the root canal was irrigated with 2.5\% $\mathrm{NaOCl}$ and the smear layer was removed using 14.3\% EDTA solution ( $\mathrm{pH} 7.2$ ) for $5 \mathrm{~min}$. The root canal was then irrigated again with $2.5 \% \mathrm{NaOCl}$ and dried with paper points. The canal was filled using non-standardised gutta-percha cones (Odous, Belo Horizonte, MG, Brazil) and sealer 26 cement (Dentsply Ind. Com. Ltda, Petropolis, RJ, Brazil), laterally condensed, and thermomechanically compacted (Fig. 11). The tooth was then provisionally sealed as described previously, and the patient was referred for permanent restoration. The patient did not return to our clinic.

\section{Case 2}

A 46-year-old woman with a non-contributory medical history was referred for root canal treatment with the complaint of episodic pain in the mandibular left second molar. The patient had a three-element partial fixed prosthesis supported by the mandibular left first premolar and first molar. During clinical examination, percussion of the tooth generated a slight response and the tooth was asymptomatic upon palpation. The mean probing pocket depth was within the normal range and no sinus tract was observed. A pulp sensibility test (Endo-Ice, The Hygienic Corporation, $\mathrm{OH}, \mathrm{USA}$ ) generated intense and persistent pain. A periapical radiograph showed unsatisfactory adaptation of the restoration, proximity of the pulp horns, and a slightly widened periodontal ligament space (Fig. 3A). Symptomatic irreversible pulpitis was diagnosed on the basis of clinical and radiographic findings, and root canal treatment in a single appointment, including pulpectomy, cleaning, shaping, and root canal filling, was proposed.

Coronal access was obtained under local anaesthesia with rubber dam isolation. The restoration and carious dentin were removed, followed by reconstruction of the proximal walls with glass ionomer cement (Vidrion R, SS White Dental Products, Rio de Janeiro, RJ, Brazil). After the identification of root canal entrances, the mesiobuccal, mesiolingual, and distal canals were explored with a \# $10 \mathrm{~K}$-file (Dentsply Maillefer) based on the root length established on the preoperative radiograph. The root canals were then prepared up to the middle third with an enginedriven device (X-Smart, Dentsply Maillefer) using S1 and S2 ProTaper instruments (Dentsply Maillefer) with a brushing motion. Recapitulation was performed with a \#10 K-file. The root canals were irrigated with $2.5 \% \mathrm{NaOCl}$ after the use of each rotary and manual instrument. The working length was established using an electronic apex locater (Novapex, Forum Technologies, Rishon Lezion, Israel) and confirmed by a periapical radiograph. The S1 and S2 instruments were then employed to the working length. Inadvertently, the F1 file was forced apically in the mesiobuccal canal, resulting in instrument fracture. The length of the file fragment was approximately $6 \mathrm{~mm}$ and it was localized in the apical and middle thirds of the canal (Fig. 3B). The patient was informed of this accidental event and the conclusion of treatment was rescheduled. Thus, the canals were dressed with a commercially prepared antibiotic-corticosteroid product (Otosporin; Farmoquímica S/A, Rio de Janeiro, RJ, Brazil) and the tooth was provisionally sealed with noneugenol temporary filling material (Cimpat, Septodont).

Three days later, the tooth was reopened under local anaesthesia with rubber dam isolation. The root canals were flushed with $2.5 \% \mathrm{NaOCl}$ to remove the intracanal

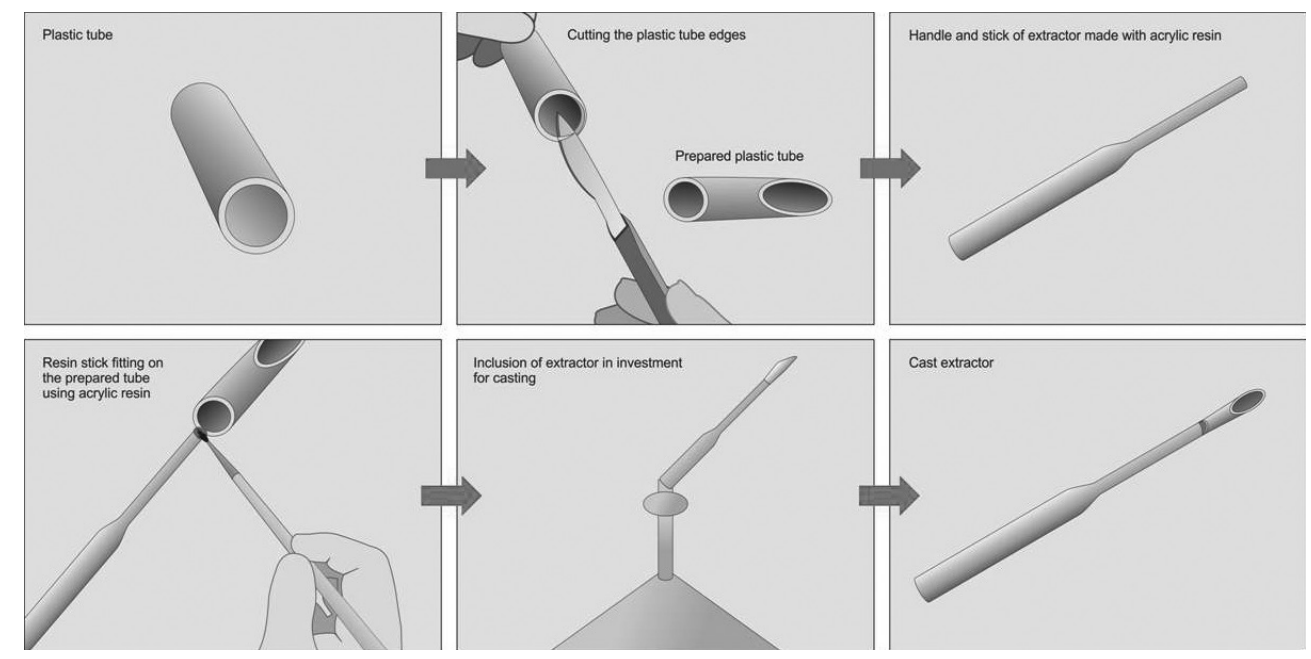

Figure 2. Schematic illustration demonstrating the manufacture of the cast customized extractor used in the Case 1 
dressing. The instrument fragment was then bypassed with a \#15 K-file (Fig. 3C). Attempted fragment removal with ultrasonic tips failed. Thus, removal using a modification of a previously described needle technique (8) was performed. The tip of a 25-gauge dental injection needle was reduced and bevelled with a carborundum cutting disc to permit the creation of a groove around the coronal portion of the fragment. The procedure used to prepare a similar instrument is illustrated step-by-step in Figure 4.

The fragment was located in the apical region of the mesiobuccal canal, which showed apical curvature to the distal region. The tip of the needle was inserted into the root canal until it contacted the cervical portion of the fragment (Fig. 3D and E). A segment of steel wire was then inserted into the needle lumen to engage the metallic fragment, enabling its removal with counter-clockwise rotation and a
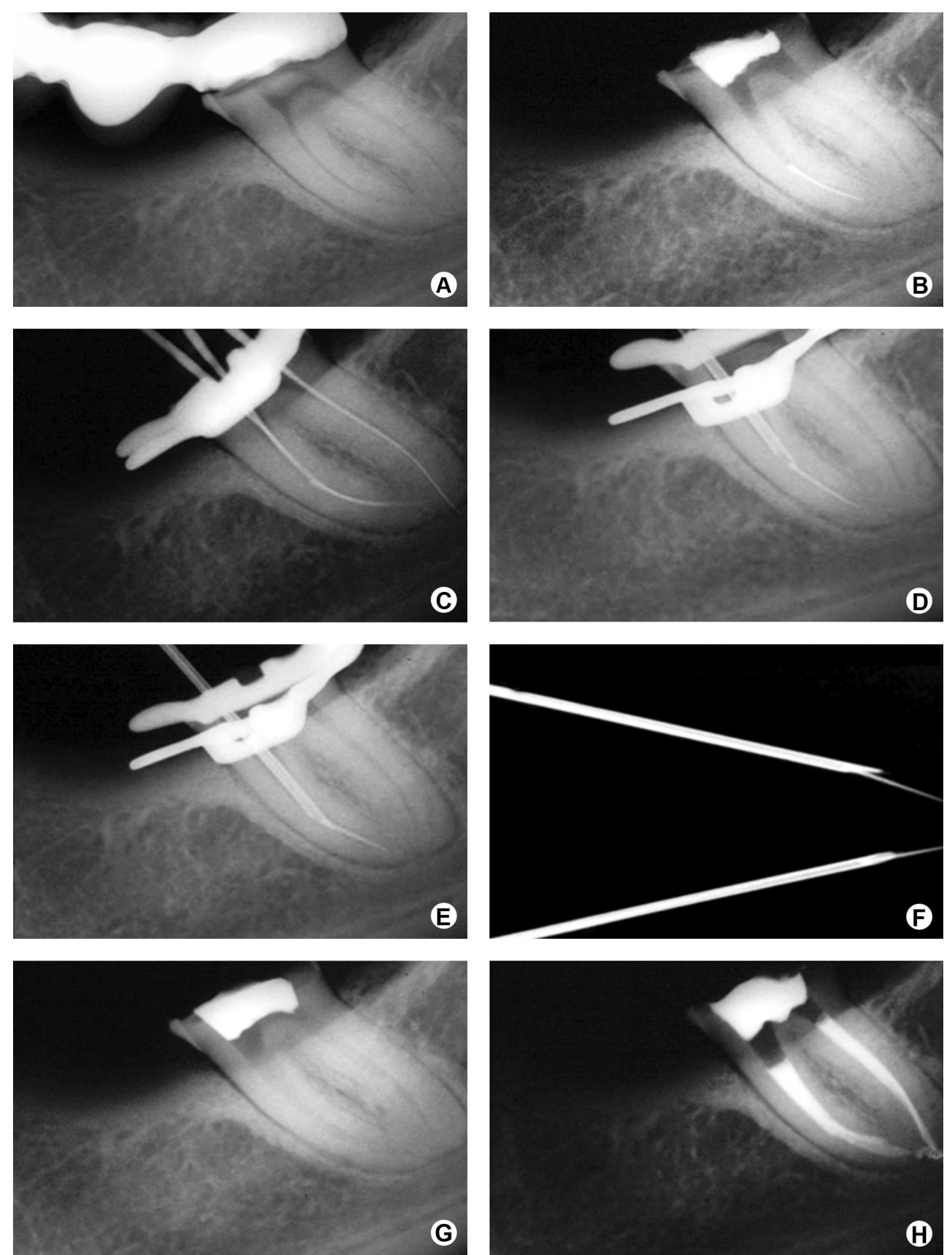

Figure 3. Sequence of fragment removal in case 2. A: Radiograph of tooth \#36 showing the presence of a fixed prosthesis with poor marginal adaptation of the crown and proximity of the pulp horns. B: Radiograph showing the presence of an instrument fragment in the mesiobuccal canal of provisionally restored tooth \#36. C: Bypassing of the fragment with a size $15 \mathrm{~K}$ file. (D and E) Insertion of the needle tip into the root canal to involve the fragment. F: Radiograph showing the fragment attached to the needle lumen. G: Radiograph of tooth \#36 with a provisional restoration after fragment removal. H: Post-obturation radiograph. 
simultaneous pull-out motion. The fragment was removed attached to the tip of the needle (Fig. 3F). A radiograph was taken to confirm file fragment removal (Fig. 3G). The canals were dressed and the tooth was sealed provisionally as described previously. At the next appointment, the tooth was reopened under local anaesthesia with rubber dam isolation and the intracanal dressing was removed. Preparation of all canals with ProTaper F2 rotary files was completed. The mesiobuccal, mesiolingual, and distal canals were then filled (Fig. $3 \mathrm{H}$ ) as described in case 1. The tooth was provisionally sealed as described previously, and the patient was referred for permanent restoration. The patient did not return to our clinic.

\section{Discussion}

Instrument fracture occurs commonly in clinical practice. It has been reported that $89 \%$ of surveyed clinicians in the UK had experienced instrument fracture
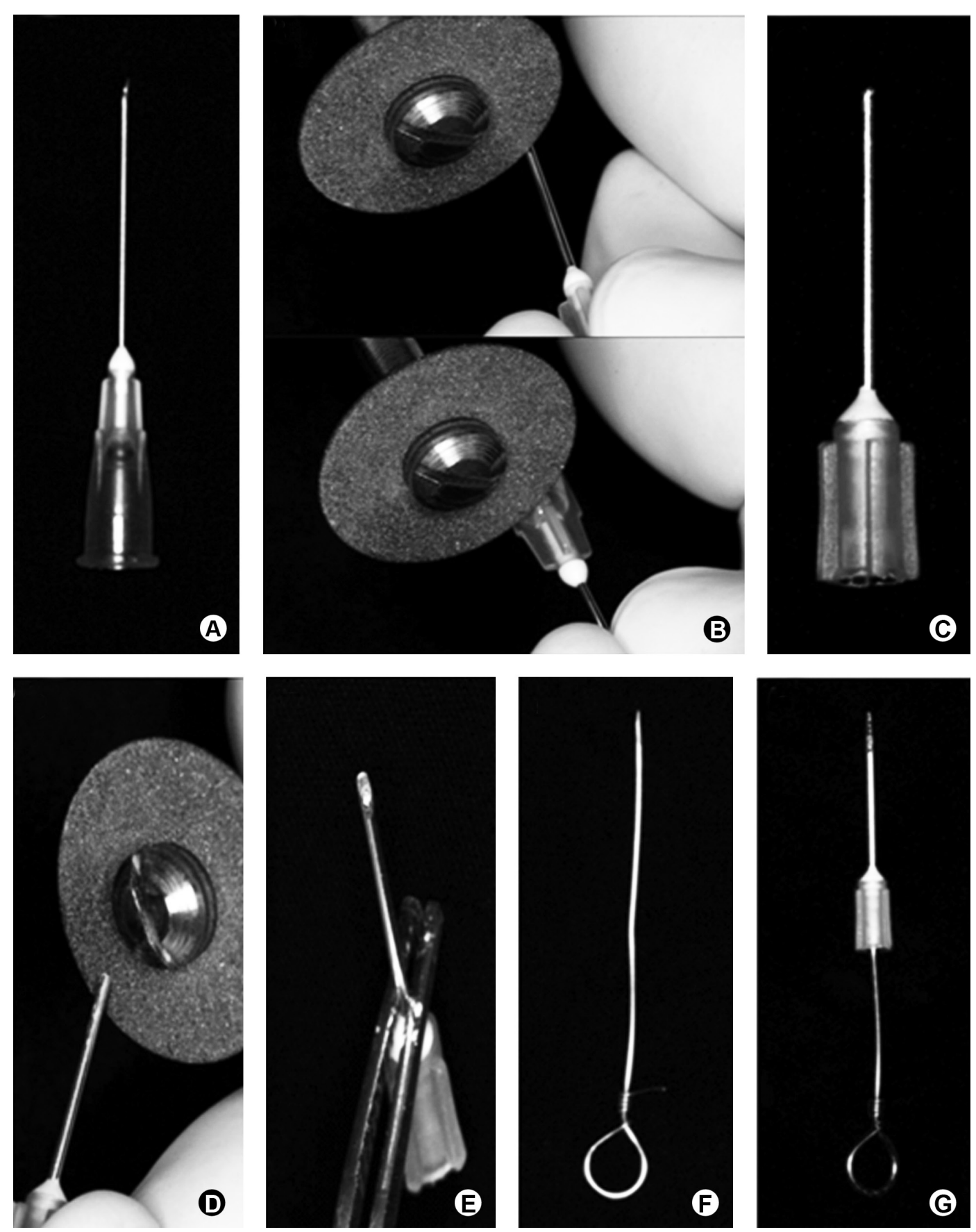

Figure 4. Modification of a 25-gauge injection needle to permit fragment removal in the case 2. A: lnjection needle. B: The base of the needle was removed to facilitate wire insertion and the tip was reduced with a carborundum cutting disc. C: Modified tip. D: The bevelling procedure. E: The bevelled tip. F: A steel wire with a ring to facilitate handling. G: Introduction of the wire into the needle lumen, with a file fragment attached to the needle tip. 
during root canal treatment (16). Such fracture can be related to several factors, such as incorrect access to the root canal, accentuated curvature of the root canal, repeated use of the same instrument, and the operator's experience $(1,2)$. The cause of instrument fracture in case 1 was difficult to determine because the patient was referred to our clinic after it had occurred. Presumably, the metallic fragments originated from burs used to obtain coronal access during initial post-trauma treatment. The absence of root canal filling and the development of apical periodontitis indicated contamination of the root canal space, but the intracanal presence of instrument fragments precluded routine root canal treatment.

Clinical situations of instrument fracture can be managed by bypassing the fragment. This procedure allowed effective removal of a small fragment located near the middle third of the root canal in case 1. However, it was not successful for the removal of a larger and more apically located fragment. Furthermore, attempts to remove apically located fragments, particularly with ultrasonic tips, can result in additional dentine removal (3). The reduction of dentine thickness in root canal walls weakens the root and can predispose it to fracture or perforation (1). Despite the rigidity of their components, extractors were found to be equivalent to an ultrasonic technique for the removal of intracanal file fragments in terms of the weakening of straight roots (4). Thus, an extractor was used in case 1 to aid removal of the instrument fragment.

The operating mechanism of the customised extractor used in case 1 was similar to that of the traditional Masseran kit, developed in the 1970s for the removal of metallic objects from root canals (5). This kit contains trepan burs for the preparation of a gutter around the most coronal part of the fragment, and a hollow tube that is subsequently positioned around the fragment. The Masseran kit also contains a plunger inside the tube that is screwed down to trap the fragment, permitting its removal $(5,7)$. In our case, a space to insert the cast hollow tube of the customised extractor was created during attempts to bypass the fragment using K-files. The fragment was entrapped with Hedström files inserted between the fragment and the tube, rather than with a plunger (11). This procedure was an essential step for removal of the metallic object located in the apical portion of the root canal of the maxillary central incisor.

Nickel-titanium (NiTi) instrument fracture rates range from $1.9 \%$ to $2.4 \%(17,18)$; fracture occurs more commonly in molars than in premolars, followed by anterior teeth (18). ProTaper rotary instruments frequently fracture in the apical thirds of root canals, and fragments of finishing files are usually longer than those of shaping files (18). Incorrect instrumentation of a root canal with a high degree of curvature increases the risk of NiTi instrument fracture. Incorrect instrumentation probably led to the fracture of the ProTaper F1 rotary finishing file in case 2 , despite the moderate curvature of the mesial root observed on a preoperative periapical radiograph. Bypassing of the NiTi file fragment enables complete preparation of the root canal and incorporation of the fragment into the filling material (1). This procedure can be used in a tooth demonstrating preoperative vitality with a favorable prognosis (19). However, intracanal fragments with lengths $>5 \mathrm{~mm}$ have been removed successfully from moderately curved canals (20). These conditions were verified in case 2 , encouraging removal.

In Case 2, attempted removal of the intracanal fragment with ultrasonic tips failed. No further attempt using this method was made to avoid the risk of excessive dentine removal. In addition, smaller fragments occasionally break off from a NiTi instrument fragment under ultrasonic vibration, leaving a shorter fragment in the root canal (20) that is more difficult to remove (1). Thus, we used a low-cost, conservative modified injection needle technique for removal (8).

Despite the similar mechanism, the technique that we used in case 2 differed in some respects from that of Roig-Greene (8). First, the previously described technique employs a wire loop passing through and protruding from the injection needle, which is tightened around the fragment. Although this loop device aids fragment removal, it requires exposure of a considerable portion of the fragment for grasping. The use of a wire without a loop, as in case 2, enabled removal of an intracanal fragment with a small exposure area. We also modified the technique to avoid use of a hemostat clamp to tighten the free ends of the wire around the fragment; rather, we used a ring on the superior part of the wire to facilitate handling during counter-clockwise rotation. Finally, bevelling of the needle in case 2 greatly improved the fit of the device around the intracanal fragment for removal. Taken together, these modifications enhanced the needle technique and provided a simple, conservative, low-cost method for the removal of intracanal instrument fragments.

In summary, this report showed that fragments of fractured instruments can be removed from the apical thirds of root canals using alternative and creative methods that reduce the amount of dentin removed.

\section{Resumo}

Este relato descreve dois casos de remoção de fragmentos de instrumentos de terços apicais de canais radiculares utilizando um extrator personalizado e técnica da agulha modificada, respectivamente. No Caso 1, um extrator foi fabricado para remover fragmento de broca localizado no terço apical do canal radicular de um incisivo central superior. 0 uso deste extrator permitiu a remoção bem sucedida e conservadora do fragmento 
de instrumento. No Caso 2, uma agulha para anestesia modificada foi utilizada como um trépano para ganhar acesso ao redor de um fragmento de instrumento localizado na porção apical curva do canal mésio-vestibular de um molar inferior. Um segmento de fio de aço foi inserido no lúmen da agulha para envolver o fragmento metálico, permitindo sua remoção com rotação no sentido anti-horário e simultâneo movimento de retração. Métodos alternativos e criativos são úteis para a remoção intracanal de fragmentos metálicos durante o tratamento endodôntico.

\section{References}

1. Parashos $\mathrm{P}$, Messer $\mathrm{HH}$. Rotary NiTi instrument fracture and its consequences. J Endod 2006:32:1031-1043.

2. Nevares G, Cunha RS, Zuolo ML, Bueno CE. Success rates for removing or bypassing fractured instruments: a prospective clinical study. J Endod 2012; 38:442-444.

3. Madarati AA, Qualtrough AJ, Watts DC. Vertical fracture resistance of roots after ultrasonic removal of fractured instruments. Int Endod J 2010;43:424-429.

4. Gerek M, Başer ED, Kayahan MB, Sunay $H$, Kaptan RF, Bayırlı G. Comparison of the force required to fracture roots vertically after ultrasonic and Masserann removal of broken instruments. Int Endod J 2012;45:429-434.

5. Masserann J. "Entfernen metallischer Fragmente aus Wurzelkanalen" (Removal of metallic fragments from the root canal). J Br Endod Soc 1971;5:55-59.

6. Madarati AA, Hunter MJ, Dummer PM. Management of intracanal separated instruments. J Endod 2013;39:569-581.

7. Okiji T. Modified usage of the Masserann kit for removing intracanal broken instruments. J Endod 2003;29:466-467.

8. Roig-Greene JL. The retrieval of foreign objects from root canals: a simple aid. J Endod 1983;9:394-397.

9. Hülsmann M. Removal of silver cones and fractured instruments using the Canal Finder System. J Endod 1990;16:596-600.
10. Kleier DJ, Mendoza M. The use of tungsten carbide needle holders to remove intracanal objects. J Endod 1996;22:703-705.

11. Suter B. A new method for retrieving silver points and separated instruments from root canals. J Endod 1998;24:446-448.

12. Nehme W. A new approach for the retrieval of broken instruments. J Endod 1999;25:633-635

13. Terauchi $Y, O^{\prime}$ 'Leary $L$, Suda $H$. Removal of separated files from root canals with a new file-removal system: case reports. J Endod 2006;32:789-797.

14. Rahimi M, Parashos P. A novel technique for the removal of fractured instruments in the apical third of curved root canals. Int Endod J 2009:42:264-270.

15. Ruddle CJ. Nonsurgical retreatment. J Endod 2004;30:827-845.

16. Madarati AA, Watts DC, Qualtrough AJ. Opinions and attitudes of endodontists and general dental practitioners in the UK towards the intra-canal fracture of endodontic instruments. Part 1. Int Endod J 2008;41:693-701.

17. Di Fiore PM, Genov KA, Komaroff E, Li Y, Lin L. Nickel-titanium rotary instrument fracture: a clinical practice assessment. Int Endod J 2006;39:700-708.

18. Wu J, Lei G, Yan M, Yu Y, Yu J, Zhang G. Instrument separation analysis of multi-used ProTaper Universal rotary system during root canal therapy. J Endod 2011;37:758-763.

19. Panitvisai P, Parunnit P, Sathorn C, Messer HH. Impact of a retained instrument on treatment outcome: a systematic review and metaanalysis. J Endod 2010;36:775-780.

20. Shen Y, Peng B, Cheung GS. Factors associated with the removal of fractured NiTi instruments from root canal systems. Oral Surg Oral Med Oral Pathol Oral Radiol Endod 2004;98:605-610.

Received February 15, 2014 Accepted December 15, 2014 